\title{
GREEK CIVIL SOCIETY'S ONLINE ALTERNATIVE NETWORKS AS EMERGENT RESILIENCE STRATEGIES IN TIME OF CRISIS
}

\section{Zafiropoulou Maria', Papachristopoulos Konstantinos ${ }^{2}$}

\begin{abstract}
The use of new communications technologies and social media, in Greece, during the time of crisis, has led to the development of numerous online informal Civil Society Networks (CSNs) (i.e. networking-building platforms, self - organized groups in Facebook, forums, exchange platforms) proposing a rethinking of the status quo of formal civil organizations. This research, utilizing the methodology of discourse analysis, aims at summarizing the rise of these networks in Greece that incorporates both solidarity initiatives and autonomous political/economic spaces and identify the indicative predictive factors of their survival and growth. Some basic conclusions that have been drawn through this research is that alternative online networks can be proven as indicative sign of the social dynamism of a given period but in order to be resilient and sustainable they should develop focal points of physical reference, pursue national representation, focus mainly on monothematic goods/services and cultivate, in several cases, links with relevant social movements and local or national NGOs. A general induction through this research is that a CSN, during this current crisis, stands between two classical models of reference in a society seeking modernity and flexibility and can be considered as a proposed type of effective experimentation and mobilization that can pursue common social goals and serve needs of deprived people. Some issues that still remain underexplored and need further elaboration are social and political identity of participants, the potential links with local, national and international communities, the functional balance be-
\end{abstract}

Dr. Zafiropoulou Maria, Msc in Political Sciences, Msc in Management of social and healthcare organizations in the University of Lille (France) and Phd in Networking social and healthcare organizations (French National School of Public Health and Institute of Administration of Enterprises) is teaching in Greek, Cypriot and Belgian universities. She has been working on several European projects, as a national Greek and French expert. She is interested on solidarity, social and healthcare networks and alternative ways of empowerment vulnerable people during the economic crisis.

2 Dr. Papachristopoulos Konstantinos is specialized in Organizational and Economic Psychology. He has completed undergraduate studies in both Psychology and Business Administration and postgraduate studies in Cultural Organizations Management, Human Resource Management, and Counseling. He has worked in counseling organizations, human resource management consultants and as a freelancer for cultural services management companies. He has been scientific coordinator for more than ten (10) research and development projects on culture and social policy and has participated in working groups at least twenty-five (25) European Programs. He has over ten years of experience in adult education in courses such as organizational psychology, management of cultural and social services, entrepreneurship and innovation, social networking and communication in organizations. 
tween structure and flexibility as well as the efficient distribution of energy between solidarity and protest.

Keywords: social media, discourse, Internet, Civil Society Networks

\section{Introduction}

Even though the term 'Civil society' is often equated with the sum total of NGOs or with the 'third sector', research has indeed shown that is not merely a bounded space between the state, the market and the citizens [Simiti, 2015]. Civil society can also been considered as "the terrain where citizens can organize to contest", but also "defend the existing distribution of power" [Kohn, 2002, p. 297] and this approach has been strengthened since the onset of financial crisis in Greece. The assumption of a wider definition of the civil society's notion is necessary in order to better reflect challenges during a crisis period in Greece and draw a holistic picture of social transformations and civic participation in Greek public space during the prolonged fluid state of suffering and transition. The alternative model of civil society's empowerment has "not only become one of the most visible symptoms of the crisis but presents, as well, a conceptual construct that attempts to place citizens' synergies in a central place, in a space that emphasizes inter-relationships too often ignored by policymakers" [Zafiropoulou, 2014, p. 25].

It is true that, in several cases, civil society mobilization in Greece tested the limits of liberal democracy but this can also be considered as a clear indication that Greek civil society had woken up and contributed to an enriched democratic life in Greece [Sotiropoulos, 2014]. Moreover, we cannot neglect the fact that suffering and economic crisis in collective consciousness among Greek people resonates with an "agonistic" ethos and an alternative view of life as a constant struggle, as well as with a symbolic metaphor of indignation [Theodossopoulos, 2014]. Thus, in Greece, during recent years of social unrest and crisis, we can claim that protest and social mobilization in the form of grassroots alternative initiatives move towards a more nuanced definition.

Despite the fact that political analysts and journalists have criticized citizens in Greece for "apathy" against instrumental brutality by the government and many ironic comments have been referred to "couch rebels" and "online protest" we cannot oversee the fact that new forms of civil alternative society's networks that emerged can also be described as the resurrection, "revival" or even as "resilience of civil society" [Sotiropoulos, Bourikos, 2014, Kantzara, 2014]. During the time when traditional political institutions lost their hold on civil society a new emerging reality opened wide space for civil society protest and creative rearrangement of social reticular organizations. This new trend was reinforced by forces such as the substantial appeal of a new global paradigm of radical activism of self organized groups, the financial difficulties Greek civil society confronted during the onset of crisis as well as the a radical shift in the institutional capacity of the State during a period of severe crisis [Simiti, 2015].

Towards the direction of new paradigm of informal and self-managed horizontal organization of CSNs social media and electronic networking platforms seem to play a dominant role in human interaction and development of self-help groups [Nadkarni \& Hofmann 2012]. Social media have become a ubiquitous part of everyday life across all the world and citizens use contemporary communication technologies for self-expression, for organizing protests, participating in self-organizing communities, exchange goods services and contributing to debates about developments in society. It is now well documented that these kinds of technologies represent a shift in democratic responsibility from institutional media to amorphous digital communities and are important to the public as they pursue personhood, identity and culture [Picard, 2014, p. 99]. 
Even though research has provided evidence that social media and internet platforms occasionally create loose and essentially leaderless networks, not capable of setting strategic goals and organizing social change [losifidis, 2011, Fucks, 2014] in times of crisis in Greece, CSNs seem to form ideal types by their principles of internal networking structure, their rationale of actors' management and their links with the external environment [Zafiropoulou, 2015].

The use of new communications technologies and social media, in Greece, during the time of crisis, has led to numerous communication exchanges among new groups of geographically dispersed people, weak informal organizations established before or during the crisis and informal volunteerism and protest at neighborhood level (i.e. neighborhood assemblies) than needed a virtual identity and organization in order to survive. These CSNs consist of networking-building platforms or self - organized groups in facebook and online forums, proposing a rethinking of the status quo of formal organizations. Thus, multiple actors, even with conflicting identities, representing civil society and in several cases protest movement such as "indignant movement" engaged meaningfully online in order to survive and expand, express their rage and activism as well as cover unforeseen upsurge in social needs in an ephemeron way. This virtual terrain of social exchange possesses the capacity to host simultaneously different voices such as volunteers struggling to offer, vulnerable groups driven by desperation and thinkers who work towards intellectual and physical protest and the generation of alternative forms of political engagement and solidarity.

This paper aims at summarizing the rise of new informal alternative online civil society networks in Greece, examine its characteristics and resilient strategies, that incorporates both solidarity initiatives and autonomous political/economic spaces and have served as focal points of protesting and support those in need.

\section{Civil Society in times of Crisis: From protesting rhetoric to a new paradigm of Civil Society Organizations (CSOs) in Greece}

Civil society in Greece during the post-dictatorial period has traditionally been defined as a weak social movement due to the presence of powerful clientelist networks and the domination of civil society by political parties [Huliaras, 2015]. Associations, in Greece do not attract adequate members and the state does not consider civic associations to be its natural interlocutors in the policy-making process [Sotiropoulos, 2015]. Recent surveys have recorded the low level of formal volunteering and social trust in Greek society [Fragonikolopoulos, 2014], decline in trust in traditional representation institutions [Eurobarometer, 79] as well as little space for civil society to grow in Greece due to the oversized Greek state [Sotiropoulos, Bourikos, 2014]. These trends have been very influential during the period of crisis in Greece leading to the emergence of a new series of non-typical solidarity networks, grassroots movements, alternative economy schemes with a common objective of providing solutions. These initiatives can be considered as an impressive social movement taking into consideration the highly individualistic Greek society [Kantzara, 2014] as well as an trustworthy expression of simultaneous expression of solidarity and protest towards corrupted political system. In parallel, the economic crisis provoked a new type of collective action and civic activism in Greece which included attacks against politicians, journalists and businessmen, occupations of public buildings, and the destruction of public and private property by radical groups.

In times of economic recession, in Greece, CSOs and CSNs, with more hybrid borders, geographical as well as organizational ones seems to be more attractive since they break out the traditional borders of the market by developing links of confidence and organizing themselves according to a method by project [Zafiropoulou, 2015]. This relative absence of hierarchic relations and transactional links constitutes an enormous change of organizational forms and the actors involved develop ephemeral agreements 
[Fabbe-Costes, 2005] since they compose, decompose and recompose constantly the organization itself. In parallel, we should not oversee that reticular organizations, such as the CSN, are outward open systems that own complex and changing dynamics, evolve in time in a non linear way, share the principles of horizontalism and decentralisation and their virtual or/and associational life is dependent on prevailing socioeconomic conditions [Fioramonti \& Kononykhina, 2015].

Loukidou [2013] in her research on formal and informal organizations points out the strong willingness of the citizens to build up informal self- organized groups as a way to be opposed to the State and to every formal attachment to the public sphere or as a more flexible way to move on in period of crises. Rakopoulos [2014] notes that their aim extends well beyond organizing a self-help association to distribute food in a poor Athens neighborhood and that cooperativisme is a new perspective able to change Greece's future. Many other scholars argue about the existence of an informal civil society in Greece even before the crisis [Sotiropoulos 2004] but we argue that since 2009 the number of informal organizations has been considerably increased compared to the formal ones ${ }^{3}$. Especially during the crisis, the use of new communications technologies has led to communication exchanges among new groups of geographically dispersed people (people who were not mobilized since now in CSNs the outsiders or weak informal organizations established before or during the crisis).

\section{Civil society's networks in times of crisis: promotion of civic engagement and linkage of dispersed individuals}

During the economic crisis in Greece, civil society's density has increased and electronic civil society networks with porous organizational borders and virtual identity represented an technological optimism since they were considered as able to contribute to the creation of an inclusive public virtual sphere of political participation, protest and solidarity. These numerous civil society's networks, created mostly during the crisis, are voluntary-based and encourage structured debates with the communal modus operandi of advocacy groups or promote organized alternative ways of life. They consist of networking-building platforms or self - organized groups in Facebook and online forums, proposing a rethinking of the status quo of formal organizations.

We argue that, during the economic crisis, formal and informal civil society networks emerged, thus becoming an ideal type and standing by themselves more and more like a privileged organizational mode. Characterized by diverse activities ranging from education, human rights, democracy, to prevention and social exclusion, the CSNs are often based on online tools such as electronic platforms, websites and blogs. Most of the CSNs are efforts made by specific social groups stricken by the crisis or even individuals and are not for profit.

\subsection{Methodology}

In order to record and analyze the self- help groups created during the crisis, the research methodology followed four (4) steps:

1. We first recorded all Facebook groups/pages following two (2) categories of target groups/members : a. unemployed people and b. people facing mental health problems, by using respective key words (a. uninsured, unemployment, unemployed people and self-help groups, self-regulated groups and b. mental health disorders, depression, stress, psychiatric problems and self help group, self regulated groups).

According to Sotiropoulos, "the Greek Centre for the Promotion of Voluntarism claims to have counted 1,800 active NGOs" (Sotiropoulos, 2014, p. 12) whereas Afouxenidis in his research records 201 active NGOs (Afouxenidis, 2015) and Kantzara notes that during her research "several talked about more than 2.500 "initiatives" (2014, p. 273). 
2. Then, only informal groups were selected (these with no legal affiliation and apparent attachment to public services, NGOs or to the State).

3. The groups were categorized in open or close groups, according to their year of creation, their main activities and their number of members.

4. Finally, a codification of the nodal concepts and attributes has been realized, using Excel 2010, in order to analyze the main discursive argumentation patterns of the members of the groups.

This research on self-regulated empowerment of Greek citizens has been conducted from September 2015 to January 2016 and aims to reflect the main tendencies of Facebook self-help groups and the increase of online CSNs during the crisis.

\subsubsection{Self-help informal groups on Facebook}

Within this contemporary crisis and during this socio-economic and political malaise citizens rally with each other, numerous self-organized solidarity movements creating social online networks and self-help groups in order to face social exclusion (marginalization, isolation, unemployment, deprivation of social goods, lack of public policies and services etc.) emerge. In Greece, the first self-help groups appear in the late 1980s and are groups of addicted people (and especially of anonymous alcoholics). During the economic crisis, the number of citizens' initiatives for the development of self-managed groups has been notably increased. We remark the quasi total absence of such self-help groups on Facebook before 2010.

\section{Self - help Facebook groups focusing on unemployed people}

The first of two self- help groups created, in 2010, by and for unemployed people remains inactive since 2011 , while the other was transformed to serve in the field of information and supply/demand for labor market. Then, a huge and sudden increase in the number of Facebook groups is noted. In total, 30 dynamic Facebook groups related to unemployment were developed during the crisis with a total membership of 30,319 (until 10/27/2015). If we relate these data with the fact that, according to Hellenic Statistical Authority (ELSTAT) from 2009 to 2011 unemployment rates doubled and many welfare structures were strongly underactive, we may conclude that this social exclusion and marginalization of the unemployed populations created the need to organize individuals and groups of them via Facebook.

The membership peak is noted in 2011 (818 members in 2010 - 976 in 2011) and 2015 (2131 members in 2014 - 30319 in 2015) while a great number of Facebook self-organized groups (10 in total) were developed in 2012. Correspondingly, in these periods of membership increase, in Greece, unemployment rate was very high $20.9 \%$ (fourth quarter of 2011) and 24,6\% (second quarter of 2015). The need to be organized and create new ways out in the internet is based rather on psychological reasons since the psychological instability of the unemployed people is very high. Psychological instability of the unemployed people is very high and their self-identity may be enhanced by being a member of a terrain of connection, sharing and solidarity. Thus, internet, and in particular, Facebook contributed substantially to form self-organized groups and informal networking of the unemployed population. Indeed, the discourse analysis revealed the desire of online self-help groups' members to find peers and rally with. However, it is noteworthy that discursive patterns reveal mobilization efforts not only to inform members about their rights but also to claim rights, beyond the context of the internet, via local and national protests in media. We argue that this form of self-organization via Facebook is a transitional stage and the beginning of civil participation that can later lead to more formal forms of organization and solidarity in real contexts. One of the informal self-help groups focusing on uninsured/unemployed persons institutionalized its efforts by creating an NGO (koinsep), which in its turn protested be- 
fore the national assembly of Greece by deposing a report emphasizing the lack of health insurance of the majority of uninsured people. In this protest, different vulnerable groups (migrants, elderly, cancer and diabetic patients), local and national NGOs and some local communities (such as health professionals of Athens as well as famous and numerous university professors) have been mobilized via online social media which addressed a call to vote on an online platform for the reporting of the "uninsured case" before the Hellenic Parliament. Thus, this initiative has been the starting point to bring to discussion and furthermore to adopt, later, a new law for uninsured people in Greece, thanks to the support of a deputy.

"Our formal power is our informal attachments.. We are informal but not invisible. The report will be defended before the Hellenic Parliament by our deputy" (Facebook comment).

\section{Self - help Facebook groups focusing on mental health issues}

In Greece, the psychiatric sector has been in constant reform since 1990. According to Zafiropoulou [2014], some psychiatric hospitals, such as the Psychiatric hospitals of Athens 'Dafni', of Corfu and Crete (Chania) have been closed and a certain number of intermediate structures such as community mental health centres (about 45) have been created before and during the economic crisis. Nevertheless, the closure of specialized hospitals and the creation of community mental health centres or psychiatry clinics in general hospitals are, unfortunately, not accompanied by a systemic vision of the mental health system. That is the reason why Greek citizens facing psychiatric issues seem to adopt a more organized way of confronting everyday challenges ${ }^{4}$. During the crisis, NGOs, have developed 220 units (30\% of all mental health units), which covers $50 \%$ of the beds of the de-institutionalization programme. These NGOs were the first victims of the crisis, since $50 \%$ of their funding was cut leading many of them to default on their operational and payroll expenses for more than six months (Oikonomou et al. 2015). Consequently, online free of charge self-help groups on Facebook appear as an alternative way to retain access to services where the State cannot support anymore, to find new niches of vulnerable persons not covered till then from public services while the government rolls back the welfare state (such as migrants or young unemployed people facing mental health problems) or to create essential synergies for the empowerment of local populations (communities).

As for the whole of $61^{5}$ Facebook groups of self-regulated people, only 12 were supported by, mainly, local NGOs strengthening their self-representation. The presence of self organized online groups related to health issues has a steady increasing trend from 2009 to 2012 (2 to 10 correspondingly), followed by a decrease of dynamism in 2013 (5 Facebook groups) and a surprising increase up to 2015, when their number

\footnotetext{
$4 \quad$ National Federation of Families for Mental Health- POSOPSY 2003, Nationwide Clustering for Psychiatric Reform 2005, Observatory for Rights in the Area of Mental Health 2006, National Committee of (ex-) Users and Survivors of Psychiatry 2010, Society of relatives of people with mental health problems KIN.A.PSY 2010, Group for people who hear voices 2010, Group for grief and sorrow 2012, Rights and Obligations of Mentally ill people, 2011

531 Mental health related Facebook groups were found for the period from 2009 to 2015, and 9 groups concerned NGOs initiatives, 22 groups were created by private operators but managed by professionals of the mental health sector. In addition, 13 groups appeared on Facebook in the years 2009 -2015 regarding depression issues and only one was supported by a NGO. During the same period, 6 Facebook groups regarding anxiety were created and two of them were the same as those presented after the analysis with the keyword "depression", probably referring to the diffuse perception of the feeling of anxiety and depression. Finally, 11 self-help groups have been created regarding stress issues and one was related to sadness (forthcoming paper Foti D., Nikolaou K. and Zafiropoulou M. "Self- regulated and resilient Facebook groups in times of crisis: the case of unemployed, alcoholic, drug takers and psychiatry patients in Greece").
} 
presented the highest possible value (15 in total). Concerning the number of members, there is an upward trend from 2009 to 2012 with a peak of the number of membership in 2012 and fast growth reaching in 2015 the highest level. However, it should be noted that this increase occurs because of the launching of an online test regarding the detection of anxiety, thus occurring a sharp concentration of about 17,000 members. It is noteworthy that this test has been the premise of 4 Facebook informal groups aiming to emphasize the tolerances and strengths of citizens in times of crisis and to unite citizens of different socio-economic and cultural backgrounds. The comments of the 17.000 participating members reveal similarities on their perceptions of solidarity, emerging resilience and interconnections on their self-presentation and "others" (politicians) representations. "We need to be united towards policy makers. Our comments reveal that it is time to change mental health sector since everyone is concerned... me, you, my child, your cousin, our boss, my neighbor... We are all equal before our stressful and even depressive life, arrogant politicians, our everyday nightmare" (Facebook comment). Therefore, the current online space has emerged as an autonomous space of solidarity.

Figure 1. Members of Facebook groups related to mental health

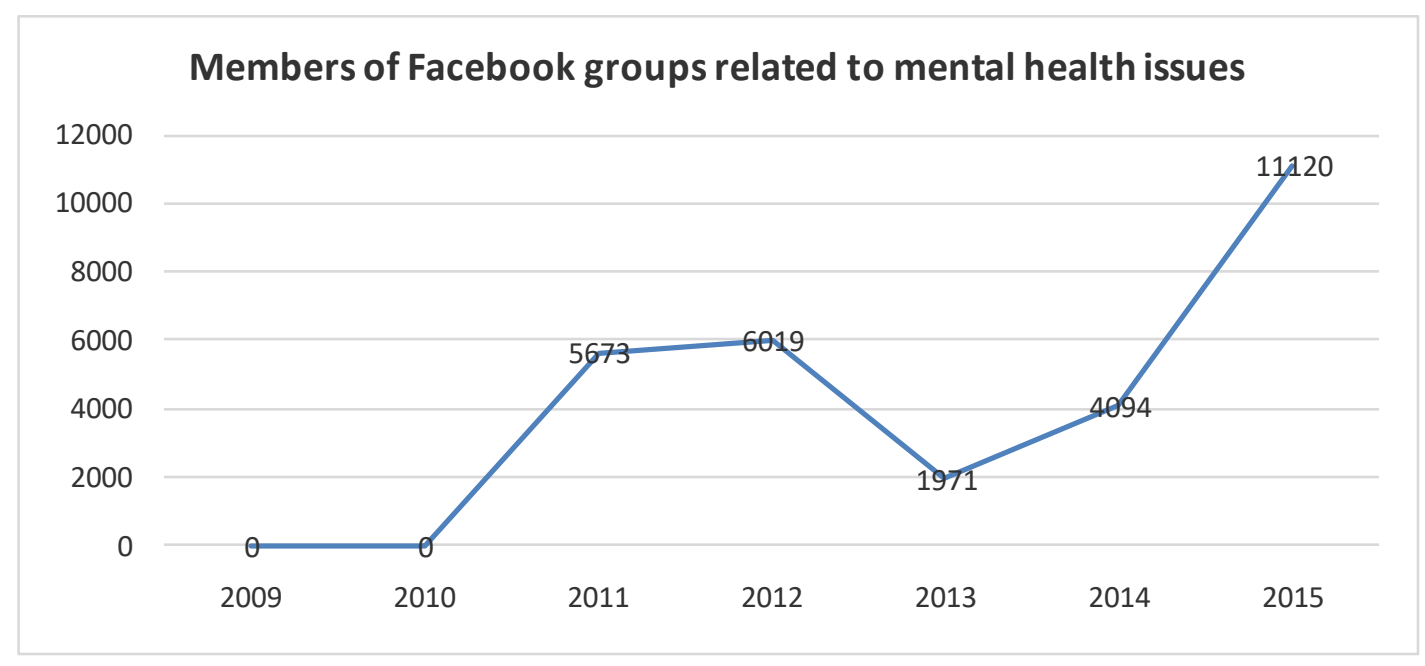

The discourse analysis of these groups revealed that the majority of these 61 Facebook self-help groups focusing on mental health issues offer different services. Only three groups focus simply on the provision of training and educational services, while 12 exchange information and experiences and 22 aim to inform and empower the civil society. The great majority raise citizens' awareness by adopting powerful slogans and mobilizing mass media, and by preparing policy guidance reports addressed to local and national policy makers. "Our duty is not just to inform you about your rights but to guide and accompany you to social public services" (Facebook comment). Thus, they do not offer just online counseling but impose bottom up solutions, constructing alternative models of transitional justice into complex socioeconomic and political environments.

\subsubsection{Electronic platforms}

The proliferation of civil society networking configurations in the internet often defy the public and normative system or the market rules. Their often embryonic and/ or competitive governance, is based on the mutual trust and volunteering. These CSNs then radically transgress the rules established by disseminating ascending practices and by reversing certain "fundamental" ones. In this case, innovation and resilience is the result of a brutal conflict with the public, legislative authorities and/or the usual 
and legitimate actors of the market. An example of this type is the creation of electronic platforms defying the market and characterized by a self positioning out of the boundaries of the law.

\section{Local Exchange Systems (LETS $\left.{ }^{6}\right)$}

LETS, i.e. Local Exchange Trading Systems (Systems of Local Exchange), is a transaction form, which does not bear interest nor produces profit, but it helps local communities to live and grow in difficult economic times. These digital representations of value that function as a medium of exchange, can be transferred, stored and traded electronically. Usually, a LETS starts from a group of people deciding to create a system. A LETS records the capacities of members and their respective needs. On the one hand there is an electrician, a plumber, a painter, a doctor and whatever other profession exists in the group. Some of them have a car and can carry people to various destinations, or have free time to watch the child of someone, or even to pay bills. A member may offer its services in the afternoon, if he/she works in the morning and another at night working and serving the system in the morning. Each unit LETS equals to the local currency. This virtual currency is not remunerated nor produces inflation; consequently it does not give profit. During the economic crisis, these communities, so far little known, experienced a great success. However, their limited geographical area and the lack of Greek people's familiarization and relevant education seem to be two of the main weaknesses of LETS. Indeed, the autonomous political and economic spaces that LETS propose based on reciprocal axiological and non-monetary incentives do not meet but a succinct and thus incomplete success.

a. The "Stakraeli" (http://www.stakraeli.gr) is an alternative social economy network in Patras, in Peloponnese. The offered products include soaps, creams, herbs, handmade jewelry, jams, vegetables, oil, etc. The services of the members indicatively include child care, nursing services, internet service provision (e.g. page construction), tutoring, moving by car etc. Even though, this community has been advertised in local mass media, membership decrease during the last years preoccupied the managers of the LETS. The only poor proposal in order to gain new members has been "to activate our mouth-to mouth-network" (comment of a member).

b. The "Mite" (Oßoגós) (http://www.ovolos.gr) is fungible social currency in which every citizen and every business can provide services to market, sell and buy products and services without the need to use Euros. The principle of the network was created in Patras and even set up as a union before the Patras Court entitled "Ovolos Currency center, social study and documentation". Once someone has at his disposal obols, has the ability to buy and sell products and services from any other member, just as he/she was purchasing in Euros. The mite has also been adopted by the network of local exchanges of Heraklion (http://www.lets.net.gr). However, the figure 2 presents the decrease of likes and posts during the last years. The discourse analysis revealed members' concern about the limited geographic area of the LETS and tried, unsuccessfully, to resolve the problem by offering 50 obols to each new member.

c. The network Exchange and Solidarity of Magnesia (http://www.tem-magnisia. gr) has adopted for exchanges between States in TEM (Local Exchange Trading System). This network is one of the oldest and most active networks in Greece with more than 2,000 registered members and an extensive list of available services and products. A TEM transfer from one member to another in the form of donation is possible. Finally, there is a platform and forum where members can discuss various issues related to the network. A similar network to that of Magnesia exists in other Greek regions such as in Evia, (Network Exchange and Solidarity of Evia - http://temevias.gr) and in Samos 
(Solidarity Network and Exchange of Samos (DI.AL.A.S- http: //www.dialas .gr.). These kind of networks seem to expand their online services attesting that "we have to raise awareness to our local community. We need to find collaborations with schools, local entrepreneurs and policy makers" (comment of TEM's manager).

\section{Support exchanges Platforms}

This section discusses electronic platforms supporting exchange of goods and services. Unlike platforms presented in the previous section, the platforms of this category use money where necessary (the transactions are conducted in Euros). This flexibility combined with specialization exchange items or services seems to be the added value of this kind of electronic platforms.

a. The "Trade Now" (http://www.tradenow.gr) is a popular trading platform (2,873 commenters) allowing the exchange of goods and services. Each member, since his/her account is created, can register vacancies (creating a list of "I") and demands (creating a list of "I want"). Each member can buy one exchange point with 1 Euro and the payment is done by PayPal. Therefore, the user can purchase a product or a service by a. giving entirely the desired exchange points to another user, b. giving some exchange points and catching up with points from his own offered item or service and c. entirely by exchanging without exchange points.

b. The "Take it - Give it" (http://partodosto.gr) is a platform for the exchange of products and services as well. The user can create a list of the desired items or services and respectively a list of items or services offered. The user has more options than in the previous platform: a. he can pay (in Euros) the amount required, or b. to propose an exchange, $c$. to haggle the price of that item or service and finally $d$. to communicate with the seller. However, the expectations of this site, based on the advertising revenues, since some subscription service for users existed, failed. This precondition seems to be a relevant limit for this kind of platforms survival.

c. The "Grant it" (http://xariseto.gr) is a nationwide network of free supply and demand items and of goods' and services' exchange without the mediation of money. In essence it is a forum of exchange community which is based on open source bulletin board phpBB. The forum has more than 50,000 members and its use is free. Correspondingly online networks are http://www.logo-timis.gr, http://antallaktiki.gr, Network Exchange Messinia "Elia" http://www. diktioelia.gr, http://babyfeat.gr (Give, exchange and create with a focus on children). Finally, the Technological Educational Institute (TEI) of Athens has started a pilot operation of a network of exchanges between members of the academic community (https://swaps.teiath.gr).

d. Tutorpool(http://www.tutorpool.gr): Its special feature is that it includes education services only. The tutorpool is a Volunteer Network and Solidarity for Education created by a group of citizens via the Internet. This network is a virtual neighborhood where people can collaborate, interact and help each other. Network's users are students, volunteers, teachers and parents and their main aim is to provide equal opportunities for each student. This platform remains very popular thanks to its specialization and its nationwide geographical coverage "I am so glad to be a volunteer in your network! I can offer my knowledge by remaining at home even to refugees, thousand of kilometers away, in Kastellorizo, and by providing some hours per month a face to face course! It is just amazing!" (comment of a volunteer). 
Figure 2. Number of posts and likes in online communities during the economic crisis

\begin{tabular}{|c|c|c|c|c|c|c|c|}
\hline \multirow{2}{*}{$\begin{array}{l}\text { Online } \\
\text { Community }\end{array}$} & \multicolumn{7}{|c|}{ Month/Year } \\
\hline & $08 / 2009$ & $05 / 2010$ & $05 / 2011$ & $06 / 2012$ & $05 / 2013$ & $05 / 2014$ & $05 / 2015$ \\
\hline \multirow{2}{*}{ Stakraeli } & & & & $4 p *$ & $5 p$ & $2 p$ & $1 p$ \\
\hline & & & & 61 & 451 & 71 & 21 \\
\hline \multirow{2}{*}{ Ovolos } & $1 p$ & $1 p$ & $1 p$ & $1 p$ & & & $1 p$ \\
\hline & 11 & 31 & 31 & 31 & & & 11 \\
\hline \multirow{2}{*}{ Hariseto } & & & & & & 361 & 11 \\
\hline & & & & & & $10 p$ & $2 p$ \\
\hline \multirow{2}{*}{ Diktioelia } & $3 p$ & & & & $0 p$ & & \\
\hline & 51 & & & & 11 & & \\
\hline \multirow{2}{*}{ Tutorpool } & & & & $78 p$ & $8 p$ & $28 p$ & $20 p$ \\
\hline & & & & 1201 & 201 & 231 & $130 I$ \\
\hline \multicolumn{8}{|l|}{ * I=likes } \\
\hline \multicolumn{8}{|l|}{ ** $p=$ posts } \\
\hline
\end{tabular}

Figure 3. Main characteristics of the electronic platforms

\begin{tabular}{|l|c|c|c|c|c|c|}
\hline & $\begin{array}{l}\text { Geographic } \\
\text { Coverage }\end{array}$ & $\begin{array}{l}\text { Change on } \\
\text { on Number } \\
\text { of members }\end{array}$ & $\begin{array}{l}\text { Change on } \\
\text { Number of } \\
\text { posts and } \\
\text { likes }\end{array}$ & $\begin{array}{l}\text { Poly the - } \\
\text { matic/ } \\
\text { Mon othe- } \\
\text { matic }\end{array}$ & $\begin{array}{l}\text { Direct or } \\
\text { i n i r e t t } \\
\text { support of } \\
\text { NGOs and } \\
\text { other or- } \\
\text { ganisms }\end{array}$ & $\begin{array}{l}\text { P h y s i c a I } \\
\text { reference }\end{array}$ \\
\hline Stakraeli & Periphery & Decline & Decline & $\begin{array}{c}\text { Polythe- } \\
\text { matic }\end{array}$ & No & No \\
\hline Ovolos & $\begin{array}{l}\text { Periphery - } \\
\text { expanded } \\
\text { in differ- } \\
\text { ent Greek } \\
\text { regions }\end{array}$ & $\begin{array}{c}\text { Stable } \\
\text { (but small } \\
\text { number of } \\
\text { members/ }\end{array}$ & Stable & $\begin{array}{c}\text { Polythe- } \\
\text { matic }\end{array}$ & No & No \\
\hline Hariseto & Nationwide & Decline & Decline & $\begin{array}{c}\text { Polythe- } \\
\text { matic }\end{array}$ & No & No \\
\hline Diktioelia & Periphery & Decline & Decline & $\begin{array}{c}\text { Monothe- } \\
\text { matic }\end{array}$ & No & No \\
\hline Tutorpool & Nationwide & Increase & Stable & $\begin{array}{c}\text { Monothe- } \\
\text { matic }\end{array}$ & Yes & Yes \\
\hline
\end{tabular}

\section{Online communities of exchange of products and services}

In addition to the platforms listed in the previous section, there are several online communities promoting the exchange of goods or services. Technically, the majority of these communities have created a blog on a free blogging service (e.g blogspot, wordpress) for the purpose of promotion and communication. In their great majority they are supported by powerful local or national Greek NGOs, and consequently their legitimacy is derived by their immediate affiliation to these NGOs. "We are glad to be independent and self-regulated. Praksis support (Greek NGO) makes our voice resonant maintaining us to an alternative mode of thinking and acting" (online comment).

Examples of such popular and successful online communities follow:

- Greek Metropolitan Social Clinic (http://mki-ellinikou.blogspot.gr) 
- Network Exchange and Solidarity Haryana (http://www.diktyo.evrytania.eu)

- Replacement Network Veria (http://antalaktikoveria.blogspot.gr)

- Syrianos Network sharing services and products (http://sanosyros.wordpress.com)

- Community Exchange (http://fasouli.wordpress.com)

\section{Conclusions - Discussion}

In extreme social, political and economic conditions new forms of relevant civic mobilization go beyond the categorization of formal or/and informal, protest/and solidarity movements, legalized or/and non-legalized collectivities and in several cases constitute a manifestation of activists effort to subvert "vertical" institutions and at the same time construct alternative "horizontal" communities [Day, 2005]. Thus, the proliferation of electronic informal initiatives in Greece can be considered as a massive social experiment of political participation, a coordinated remedying effort to response to the rising levels of social exclusion and poverty, an indicative sign of a political radicalization process [Simiti, 2015], as well as an enhancement in the quality of citizenship and enriched democratic life [Sotiropoulos, 2015]. Nevertheless, while online associationism is now empirically recorded in Greece, the remaining question to address is whether under certain condition these alternative networks can contribute to sustainable democracy and to the creation and expansion of the public sphere.

One basic conclusion that has been drawn through this research is that alternative online networks can be proven as indicative sign of the social dynamism of a given period but in order to be resilient and sustainable, and not being displaced by the newest 'big thing', they should not depend only on the durability and the stability of the cooperation's links, but also on the capacity of its rationally limited members to stabilize the cooperation within a global hierarchical system of the market. Moreover, we cannot oversee that despite the fact that locally led alternative networks seems to attract more members (e.g. The network Exchange and Solidarity of Magnesia and Stakraeli), in long term the networks of national representation exhibit more resilience and effective capacity to transform and adapt in fluid social environments (e.g. Grant it and Take it-Give it). In addition to this, social collectivities that had been established prior to crisis, in a more stable environment with minimum formal organizational structure and developed side alternative activities (i.e. electronic exchange platforms) during the crisis, exhibit ability to fully utilize their potential as a power for efficient transformation. Indeed, the examined Facebook groups developed during the crisis in collaboration with some powerful NGOs of the mental health sector (e.g. Praksis) take advantage of the organizational and networking stability of these NGOs and are more keen to develop new activities and survive in the changing environment. This stability of the cycle life of informal online groups is highly linked to the juxtaposition of stable collaborations, and thus the strategies of such alternative groups of protest appear as more resilient. Moreover, societal, institutional and/or political support is an essential element for the evolution and survival of these CSNs (see figure 3).

We can also conclude by the sample of CSN's (Facebook and online platforms) examined that a virtual terrain of protest, transaction or/and communication is being reinforced by a focal point of physical reference. This way networks that had established a place of regular consultation (i.e. offices, assemblies, local events) seem to develop a more stable pattern of operation and more dynamic presence online and "offline" (i.e. during mass rallies).

In parallel, a noticeable emergent pattern through current research is that online communities that focus on monothematic services or/and products (e.g. Tutorpool, Facebook groups of patients) are more resistant towards time depreciation and form potentially a role model for replication. Thus, we could predict that during times of crisis a self - help online community about women refugees victims of violence would be 
more resilient compared to a multidisciplinary focus on human rights in general since in the first case scenario more committed participants might be on board.

Overall a CSN, during this current crisis, stands between two classical models of reference in a society seeking modernity and flexibility, that has emerged the network organization as a new ideal type [Livian, 1998]. They break out the traditional borders of the market by developing links of confidence and organizing themselves according to a method by project or emerging needs (i.e. exchange of goods). Despite their flexibility and wealth, CSNs are not but a possible alternative. We cannot reduce the analysis of the CSN at this of a device with the service to local populations or at this of a "passepartout", open to every participative and changing experimentation of the field. Indeed, it would be inappropriate to reduce the CSN at its mythical, imaginary and symbolical dimensions or at its classification of ideal type, since it does not have a seminal value. In this dynamic perspective, every CSN will be characterized by the partial or total entanglement of the three levels (hierarchy, network, market) that depend on mechanisms of regulation and organizational arrangements sustained, driven or generated within it.

Alter's approach $(2009,2003,2002)$ could be utilized as a proposed evolutionary process towards CSNs transformation to resilient solidarity and protest schemes since it considers transgression as an integral part of innovation process. Transgression moves hand by hand with innovative civic behavior (see Figure 4) and serves as a path linking the actors, heterogeneous and sometimes contradictory processes and services in a permanent disorder leading to (social) innovation through the local tinkering, the ownership and the institutionalization. The transgression of the rules represents a kind of anticipation to the development of institutions and is not so scandalous since it is not an end in itself but only a mean to produce a novelty that does not fit into the usual routine. Alter compares innovators to smugglers and deviant and supports that the innovative, without compromising their individual characteristics, is often a impassioned and sometimes passionate person. Following, his theory, members- leaders of informal online CSN can be more innovative- resilient than formal managers thanks to their flexibility, their axiomatic values and their positioning against State.

Figure 4. Lexical (ATLAS) and thematic (Sphinx) analysis of concepts of innovation and transgression

The first finding of the lexical and thematic analysis conducted on comments and posts of the online alternative Facebook groups and electronic platforms is the massive use of expressions such as "we must and I have to". The mandatory nature is the most recurrent feature premium on political regulation and modes of innovation within a CSN. The second observation is the use of nouns and adjectives which present a very important relationship in the case of innovation, while in the case of transgression are modal phrases that are often used.

Lexical analysis of the speeches of the members related to the occurrence of innovation reveals two classes: one referring to the question of transgression and the second to innovation.

\section{Class 1: "Transgression"}

The class 1 refers to the issue of non-compliance with the rules, even if the word transgression is not evoked directly (the word deviance appears only five times). "Softer" words such as compliance or failure are used to refer to all kinds of transgression of the rules. These vocals are not considered as people's statements to avoid the rules but in the contrary to act in an alternative way.

The specific vocabulary of this class is the following:

- Need ( 57 times), it should not be (42 times), it is important (34 times), there is a need (35 times), we have to (26 times), I have to (21 times).

- Law (54 times), rulers (22 times), authority (18 times), society (46 times), failure (53 times), non-compliance (22 times), deviance (5 times). 
- Self-Regulate (57 times), respect (15 times), deflect (21 times), overflow (12 times), authorize (45 times), control (46 times), prohibit (28 times).

\section{Class 2: "Innovation"}

The class 2 focuses on the concept of innovation, as perceived by online members/commenters. Innovation is often confused with the organizational novelty associated with new information and communications technology (ICT). A strategic vision, not only of CSNs, but the general competitive environment in times of crisis is a prerequisite for its occurrence. It is the creativity and originality of a process or project that confer innovation. Also, it is noteworthy that creating online communities and pressing policy makers are regarded by the members as the greatest innovations of the Greek civil society.

The specific vocabulary of this class is as follows:

- Research (45 times), populations' needs (48 times), development (21 times), organizational innovation (38 times), technology (42 times), online community (32 times), creation (44 times), originality (22 times) novelty (44 times), change (10 times) requirements (12), arranging (25 times), vision (55 times), capacity (24 times), strategist (43 times), pressure of policy makers (88 times).

- Original (13 times), technology (20 times), traditional (12 times), changing (15 times), singular / single (28 times), prototype (21 times).

- Create (47 times), change (21 times), computerize (21 times), fit (12 times), learning (10 times).

Policies of installation, development and survival of a CSN must adapt to its sometimes unstable and changing environment. It is then its organizational capacity of interference and arrangement in time which will make a CSN innovative, resilient and sustainable. Nevertheless, we cannot also neglect to notice a gap between social media and networks capacity to mobilize citizens (i.e. sharing of information, unstructured participation) and their ability to initiate and maintain meaningful and sustainable dialogue that maximize the impact of solidarity actions and relevant protest (i.e. forming of new political identities, initiate public dialogue and critical discussion). We should remain cautious about whether citizens' online communities, during crises, can effectively both serve a two-fold goal namely facilitating solidarity and remedying actions when governments rolls back the welfare state and in the same time being "indignant" towards cuts in public spending, salaries, pensions and welfare benefits. Moreover, some issues that still remain underexplored and need further elaboration are social and political identity of participants, the potential links with local, national and international communities, the functional balance between structure and flexibility as well as the efficient distribution of energy between solidarity and protest.

\section{References}

AFOUXENIDIS, A. (2015). Civil society in times of Crisis (in Greek) in N. Demertzis, N. Georgarakis, N. (eds.) The political portrait of Greece: Crisis and degradation of Politics, Athens: Gutenberg (pp. 317-336).

ALTER, N. (2002), Les logiques d'innovation, Paris, La Découverte.

ALTER, N. (2003), Régulation sociale et déficit de régulation, G. de Terssac, La théorie de la régulation sociale de Jean-Daniel Reynaud, Paris, La Découverte, p. 77-88.

ALTER, N. (2009), Donner et prendre, la coopération en entreprise, Paris, La Découverte.

BOURIKOS, D. (2013). Social Solidarity in Greece in times of crisis: New wave of emergence of civil society or consolidation of fragmented social citizenship?, (in greek), ELIAMEP. Crisis Observatory, Athens.

DAY, R. (2005). Gramsci is dead: Anarchist Currents in the Newest Social Movements, London: Pluto Press. 
FABBES - COSTES N. (2005). La gestion dynamique des supply chains des entreprises virtuelles. Revue Française de Gestion, 31, 156, p. 151-166.

FIORAMONTI L., KONONYKHINA O. (2015), Measuring the Enabling Environment of Civil Society: A Global Capability Index, Voluntas, 26(2), pp. 466-487

FRAGONIKOLOPOULOS, C. (2014). Politics, the Media and NGOs: The Greek experience, Perspectives on European Politics and Society, 15(4), pp. 606-619.

FUCHS, C. (2014) Social Media: A Critical Introduction. London: Sage.

HOMER - DIXON T. (2001), The Ingenuity Gap, Toronto, Vintage Canada.

HULIARAS A. (2015), Greek Civil Society in Times of Crisis: The Neglected Causes of Weakness in J. Clarke, A. HULIARAS, D. SOTIROPOULOS (eds.), Austerity and the Third Sector in Greece: Civil Society at the European Frontline, London: Ashgate (pp. 9-28).

IOSIFIDIS P. (2011).The Public Sphere, Social Networks and Public Service Media' Information, Communication \& Society. 14(5): 619-37.

KANTZARA V. (2014), Solidarity in times of Crisis: Emergent Practices and Potential for Paradigmatic Change. Notes from Greece, Studi di Sociologia, 3, pp. 261-280.

KOHN M. (2002). Panacea or Privilege? New Approaches to Democracy and Association, Political Theory, 30(2), pp. 289-298.

LIVIAN Y.F. (1998). Organisation, Théories et pratiques, Paris: Dunod.

LOUKIDOU K. (2013),"Formal and informal civil society associations in Greece: two sides of the same coin?"Paper for the 6th Hellenic Observatory PhD Symposium on Contemporary Greece and Cyprus, Hellenic Observatory, European Institute, LSE, 6-7 June 2013

NADKARNI, A., HOFMANN S.G. (2012). Why do people use Facebook? Personality and Individual Differences, 52(3):243-249.

OIKONOMOU C., KAITELIDOU D., KATSIKAS D., SISKOU 0., ZAFIROPOULOU M. (2014). Impacts of the economic crisis on access to healthcare services in Greece with a focus on the vulnerable groups of the population, Social Cohesion and Development, 9(2), 99-115.

PETROPOULOU, C. (2013). Alternative Networks of Collectivities' and 'Solidarity Cooperative Economy' in Greek cities: Exploring their theoretical origins, Journal of Regional Socio-Economic Issues, 3(2), pp. 61-85.

PICARD R.G. (2014). Panel I: The Future of the Political Economy of Press Freedom, Communication Law and Policy, 19(1): 97-107.

SIMITI M. (2015). Social Need' or 'Choice'? Greek Civil Society during the Economic Crisis, Discussion Paper no. 95, Hellenic Observatory, European Institute, LSE.

SOTIROPOULOS D, BOURIKOS D. (2014), Economic Crisis, Social Solidarity and the Voluntary Sector in Greece, Journal of Power, Politics and Governance, 2(2), pp. 33-53.

SOTIROPOULOS D. (2004), Formal Weakness and Informal Strength: Civil Society in Contemporary Greece, Discussion Paper no. 16, Hellenic Observatory, European Institute, LSE.

SOTIROPOULOS D. (2014), Civil Society in Greece in the Wake of the Economic Crisis, Research Paper, Konrad Adenauer Stiftung \& ELIAMEP, Athens.

THEODOSSOPOULOS, D. (2014). The Ambivalence of Anti-Austerity Indignation in Greece: Resistance, Hegemony and Complicity. History and Anthropology, 25(4), 488-506.

ZAFIROPOULOU M. (2014). Exclusion from Healthcare Services and the Emergence of New Stakeholders and Vulnerable Groups in Times of Economic Crisis: A Civil Society's Perspective in Greece. Social Change Review, Winter 2014, vol 12 (2) 2): 141-160.

ZAFIROPOULOU M. (2015). Theoretical "Regulation- Proximity" model ", Deliverable R-2015-10, project Fragmex, November 2015, Hellenic Open University. 